\section{A COMMENTARY ON NELSON'S "XENOGRAFT AND PARTIAL AFFECTIONS"}

\author{
WILLIAM AIKEN \\ Chatham College
}

By developing his argument from "partial affection," Nelson has attempted to justify xenograft without having to "impartially" defend species partiality. It is an interesting tack, but I am afraid that it is not all that useful in settling the moral controversy over xenograft. I will show this by setting up a parallel case of partial affection involving xenograft, show how it meets most of Nelson's considerations justifying partiality, and then raise the question whether he would accept my case or if, in rejecting it, he must return to some species partiality argument.

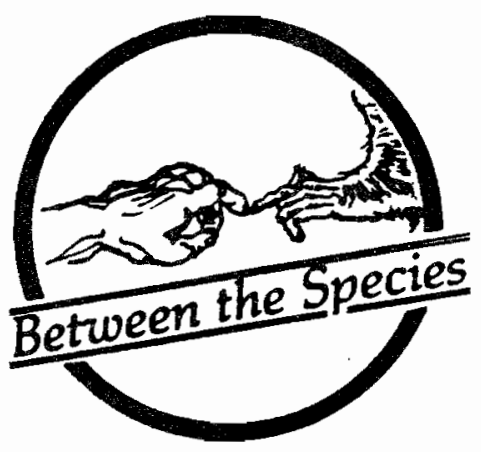

My case just reverses the donor and the donee. The ailing patient is my pet chimp with whom I have a strong personal bond of love; a love worthy of admiration and which has moral value, for our "histories are intertwined in significant ways." This love and its consequent value are not universalizeable and my partiality is neither "extreme" nor "unquestioned." Nor does this love prevent my respecting other sources of value. My chimp needs a kidney to continue living. suppose that no chimp kidneys are available, that xenograft techniques have been perfected, and that no human kidneys are available through conventional sources. But I could purchase one from a black-market dealer who kills and then sells the body parts of extremely impoverished but otherwise normal children whom he/she has found aban- doned (and thus unloved) in the back streets of some third world megapolis. Would I, as a loving pet owner, be faced with a real moral dilemna like the one proposed by Nelson wherein "the claims of impartial reason and the claims of partial affection are both morally respectable"? could I justifiably decide in favor of my chimp and choose to use the human solely as a means to my chimp's end?

The considerations which Nelson raises seem to apply in my case as well. I am not granting any claim of species partiality but am basing my partiality on personal affec-

tion. I need not endorse the questionable practice for obtaining the organ (the blackmarket dealer) in order to accept the justifiability of my private decision. The fundamental interest at stake and the lack of alternatives for his/her child and my chimp are similar. Refusal to buy the kidney is not certain to save the child from death, but buying it will save my chimp. I could work for economic and social reform in that third world nation or for some control of exploitive organ trading and thus I could still show my respect for impartial considerations and my respect for "subjects of a life" that are human. And finally, because the "donor" in this case was not a marginal human, he/she is exempt from Nelson's "tragedy of marginal cases" argument. Our cases seem similar in all relevant respects. Affection alone seens to tip the scales in justifying the personal decision.

Nelson can do one of three things with my case. First, he can see it as a reductio and withdraw his claim that partial affection alone can justify xenograft involving killing when species impartiality is assumed. Second, he can accept the implication of my case and affirm that sometimes we may justifiably use as a mere means an unloved human to preserve a loved non-human. Since species is irrelevant and since killing in one case is permissible, killing in the other case is permissible provided that the one saved is loved and the one sacrificed is not. Third, and I suspect he would choose this option, he could try to show how my case is relevantly

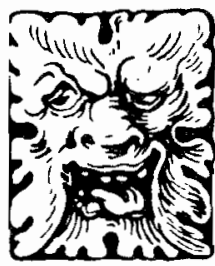

DISCUSSION 
different from his. He could do this by evoking the one consideration on his list which I did not transfer over into my case, that "it is at least plausible that death is a greater harm to the child than to the baboon. The child's death may foreclose a greater range of satisfaction and preclude projects of greater moral worth." So, he could argue that his case is different from mine because it is plausible that a child's death is a greater harrn than a baboon's death, whereas it is not plausible that my chimp's death is a greater harm than the death of the abandoned child. Thus, his sacrificing the baboon is not beyond moral limits, but my sacrificing the child is, because of the comparative worth of the beings in question.

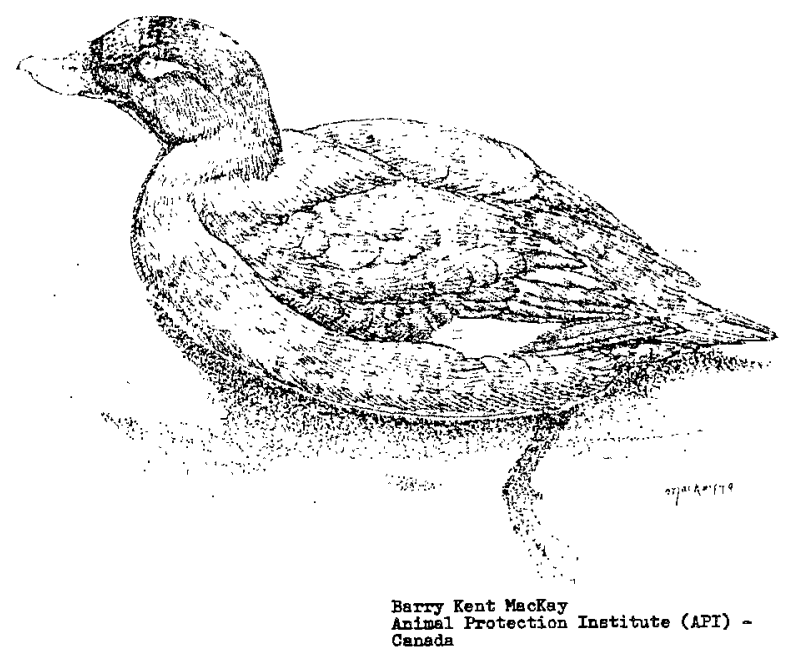

If he took this stance, we could interpret him in two different ways. Either he would mean that a particular child (Baby Fae) compares favorably to a particular baboon (Goobers) or generally any human compares favorably to any non-human. Comparing particular individuals leaves open the possibility that some non-human would be judged to be of greater moral worth than some human and thus if greater moral worth is a relevant consideration in sacrificing a non-human for a human, then it would also be relevant in sacrificing a human for a non-human. My chimp may indeed have greater moral worth than some human who is not "marginal" (for instance, a vicious and violent psychopath). so, sometimes my chimp should win.

However, I imagine that Nelson would want to endorse the general clain that it is plausible that the human species is superior in moral worth and thus members of this spe- cies should take precedence in conflict situations. If so, then we seem to be back to the issue between Frey et. al. on whether species partiality can indeed be "impartially" justified on grounds of comparative moral worth. Partial affections do not, it seems, play any role in this crucial and I think pivotal question of comparative moral worth unless you beg the question by asserting that because all and only humans are in loving relationships they automatically have superior moral worth. In fact, the argument from partial affections doesn't add much at all to the xenograft debate other than perhaps to explain parental motives if xenograft is morally permissible, and to mitigate moral blameworthiness if it is not. So, I am not convinced that this interesting tack via partial affections is at all helpful in deciding whether xenograft is right or wrong.

\section{ANIMALS. Do they matter?}

An exciting new awareness is unfolding about our relationship with animals and the rest of the natural world. Read about it in THE ANIMALS' AGENDA.

THE ANIMALS' AGENDA gives you news, views and articles about animal rights, welfare and protection, and about the people who are making animal rights one of the major issues of the 80$)^{\prime}$.'.

A WHOLE MOVEMENT

IN (INE: MAGAZINE. TRST LSSUE FREE!

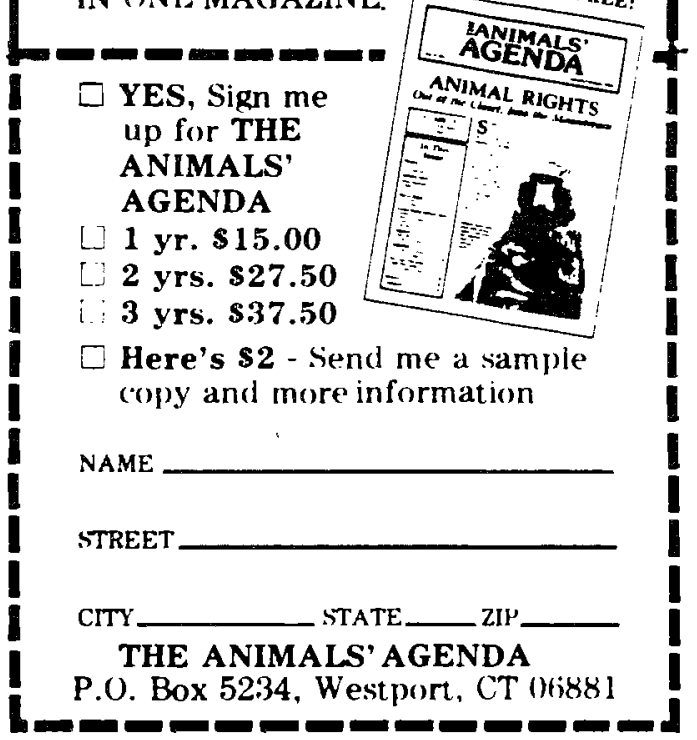

